\title{
Depression and Hopelessness in Institutionalized Elderly: A Societal Concern
}

\author{
Kamna Sarin, Punyaapriya P, Sanjoni Sethi, Itisha Nagar \\ Department of Psychology, Kamala Nehru College, University of New Delhi, New Delhi, India \\ Email: kamnasarin9@gmail.com
}

Received 8 July 2016; accepted 13 August 2016; published 16 August 2016

Copyright (C) 2016 by authors and Scientific Research Publishing Inc.

This work is licensed under the Creative Commons Attribution International License (CC BY). http://creativecommons.org/licenses/by/4.0/

(c) (i) Open Access

\begin{abstract}
Even though occurrence of depression in older adults is considered a major public health problem, very few Indian studies have made an attempt to study the mental health of elderly residing in institutionalized settings such as nursing homes and old age homes. The purpose of this study is to examine the presence and severity of depression and extent of negative attitudes about the future in institutionalized elderly in India. Data were collected by administering the Beck Depression Inventory (BDI) and Beck Hopelessness Scale (BHS) on residents of different old age homes across Delhi NCR ( $\mathrm{N}=21)$. Results revealed presence of mild depression and mild hopelessness in the institutionalized elderly. Further, a positive strong correlation was found between depression and hopelessness $(\Gamma=0.83)$. Social and emotional losses associated with institutionalization are likely to lead to depressive responses in the elderly. The findings of the study draw attention to the neglected and apathetic conditions of institutionalized elderly, an imperative concern for the Indian society.
\end{abstract}

\section{Keywords}

Depression, Elderly, Institutionalized Elderly

\section{Introduction}

"Depression dawns as gradually as adulthood"-Solomon.

Similar to any physical health, mental illness is the sickness of the mind. The sufferer describes themselves in a state of confusion, unpredictability and complete mess. It is not unusual for people to feel unpleasant, melancholic and wretched; however, continuous grief, pain and miserableness are expressions of dysfunctional thought and irrationality.

A toxic aspect of depression is hopelessness which is characterized by a negative cognitive style and feelings of futility regarding the future goals (Carson, Butcher, Mineka, \& Hooley, 2007; Duran \& Barlow, 2000). It is 
conceptualized as an individual's state of extreme pessimism regarding the negative consequences of life events (Whipple, 2009). Cross-sectional studies have found an association between depression and hopelessness symptoms (Bagge, Lamis, Nadorff, \& Osman, 2014). However, hopelessness may also occur independent of depression or as a precursor to depression (Dunn, 2005).

Today, depression is an important public health challenge in developing countries. This problem is not new; in 1990, the World Health Organization (WHO) described depression as a major, worldwide cause of disability (Pilania, Bairwa, Kumar, Khanna, \& Khurana, 2013). Lifetime prevalence rates of depression range from $8 \%$ to $12 \%$ in most countries (Andrade, 2003).

Particularly vulnerable group is the geriatric population as depression in older adults and the elderly are often linked to physical illness. For many experiences related to the disorder such as the demands of managing a chronic disease, functional limitations or pain due to the disease, and vision or hearing loss can provoke a depressive reaction (Djernes, 2006; Vink, Aartsen, \& Schoevers, 2008). Other more subtle factors that lead to a loss of self-identity or self-esteem may also contribute (APA, 2010). Further, emotional and physical suffering decreases the quality of life and increases the risk for death among older adults (Blaze, 2003).

Community-based mental health studies have revealed that the point prevalence of depressive disorders among the geriatric population in India varies between 13\% and 25\% (Nandi et al., 1997; Barua \& Kar, 2010). The mental health of senior citizens in India is a major concern considering that they constitute $7.5 \%$ of the total population. Recent epidemiological studies done in India have reported that senior citizens are at an increased risk of developing a mental disorder (Math \& Srinivasaraju, 2010).

A combination of lifestyle changes and urbanization has led to the change in family structure and pattern, thus, leading to the emergence of institutionalized homes in India. Separation from family is difficult for any individual at any stage. Institutionalization of elderly is especially hard as changing one's residence can create further pressures as being "uprooted” which causes a sense of helplessness and excessive stress (Puwac, 1995).

The risk of depression increases in the case of the institutionalized elderly rather than those who live in the community or in their own families. In many cases, the lack of social support from extended family or community can lead to the elderly person's loneliness and social isolation (Runcan, 2012). There seems to exist a perceived notion that institutionalization leads to loneliness and social isolation (Runcan, 2012).

The present study aimed to assess the presence and severity of depression and hopelessness in institutionalized elderly.

\section{Method}

\subsection{Participants}

Institutionalized elderly of different old age homes $(\mathrm{N}=21)$ of age group (above 60 years) from New Delhi and NCR (National Capital Region) were selected for the present study which was conducted over the period of 5 months. The demographic details of the participants have been provided in Table 1.

\subsection{Measure}

Beck’s Depression Inventory-II (BDI-II, Beck, Steer, \& Brown, 1996). The BDI-II has become the most widely used psychometric measure of depression severity (Beck et al., 1996). The BDI-II is used to assess the severity of depressive symptoms in clinical populations and is commonly used to detect the presence of depression in general population samples. BDI-II is a 21 item questionnaire using a 4 point scale. The scores range as minimal range (0 - 13); mild depression (14 - 19); moderate depression (20 - 28) and severe depression (29 - 63). The recommended sensitivity and specificity of the scale is 88.2\% and 92.1\% (Smarr \& Keefer, 2011).

Beck's Hopelessness Scale (BHS, Beck, Weissman, Lester, \& Tvexler, 1974). The BHS adheres closely to Stotland's concept of hopelessness as a system of cognitive schemas in the future (Scotland, 1969). The BHS is used to measure the extent of negative attitudes about the future in adolescents and adult population. The BHS consists of 20 True and False statements. The score ranges as minimal (0 - 3); mild (4 - 8); moderate (9 - 14) and severe (15 - 20). Both, the sensitivity and specificity of the scale has been found to be 95\% (McMillan, Gilbody, Beresford, \& Neilly, 2007).

\subsection{Procedure}

A brief case history was taken from the participants including age, educational qualification, relationship status 
and physical illness. The participants were then presented with two questionnaires (BDI-II and BHS). Participants were asked: 1 ) to rate their feelings on a rating scale of 0 to 3 (not at all to severely) and 2) describe their attitude indicating "true" or "false" for the given statements.

\subsection{Statistics Analysis}

Firstly, percentage was calculated of individuals based on demographic characteristics of the participant including gender; age; educational qualification; period of stay; financial support and spouse. Secondly, percentage of individuals with mild; moderate; and severe depression were calculated. Similarly, percentage of individuals with mild; moderate; and severe hopelessness were calculated.

Finally, descriptive statistics were obtained noting mean and standard deviation for the two variables (depression and hopelessness). Pearson correlation was calculated to observe the relation between depression and hopelessness with $p<0.05$.

\section{Ethical Clearance}

This research paper ensures the conduct and practice following research ethical guidelines. A Centralized Ethical Board does not exist in India, however, accuracy; fairness; intellectual honesty and property has been maintained. Protection and rights of the human participants were thoroughly ensured and no harm was caused. Informed consent was taken from the participants; anonymity and confidentiality was ensured for the collected data. Further, in cases of high score obtained, counseling sessions were offered to participants.

\section{Results}

For each participant demographic details were collected that has been presented in Table 1 . The period of stay ranged from 3 months to 9 years. Majority of the participants were suffering from a physical illness including diabetes and arthritis amongst other illnesses.

Table 1. Demographic characteristic of the participant.

\begin{tabular}{|c|c|c|c|}
\hline & Demographic Characteristics & Sample & Percentage \\
\hline \multicolumn{4}{|l|}{ Gender } \\
\hline & Male & 7 & 33.33 \\
\hline & Female & 14 & 66.66 \\
\hline \multicolumn{4}{|l|}{ Age } \\
\hline & $60-70$ & 4 & 19.04 \\
\hline & $71-80$ & 11 & 52.38 \\
\hline & $>81$ & 6 & 28.57 \\
\hline \multicolumn{4}{|c|}{ Education Level } \\
\hline & $<10^{\text {th }}$ Class & 3 & 14.28 \\
\hline & $12^{\text {th }}$ Class & 3 & 14.28 \\
\hline & Graduation & 5 & 23.80 \\
\hline & Post-graduation & 8 & 38.09 \\
\hline & Doctorate & 2 & 9.52 \\
\hline \multicolumn{4}{|c|}{ Period of Stay } \\
\hline & 0 - 1 year & 7 & 33.33 \\
\hline & 2 - 5 years & 11 & 52.38 \\
\hline & $>5$ years & 3 & 14.28 \\
\hline \multicolumn{4}{|c|}{ Financial Support } \\
\hline & Self & 9 & 42.8 \\
\hline & Self and Other sources & 4 & 19.04 \\
\hline & Others (children, relative etc.) & 7 & 33.33 \\
\hline & Institution & 1 & 4.76 \\
\hline \multicolumn{4}{|l|}{ Spouse } \\
\hline & Deceased & 16 & 76.19 \\
\hline & Living Separately & 4 & 19.04 \\
\hline & Unmarried & 1 & 4.76 \\
\hline
\end{tabular}


Percentage of individuals with mild, moderate and severe depression and hopelessness have been presented in Table 2 and Table 3. Additionally, Pearson correlation was computed to observe correlation between depression and hopelessness in institutionalized elderly in India that is presented in Table 4.

Table 2. Percentage of individuals with mild, moderate and severe depression.

\begin{tabular}{cc}
\hline Depression & Percentage \\
\hline Minimal & 33.33 \\
Mild & 38.09 \\
Moderate & 23.80 \\
Severe & 4.76 \\
\hline
\end{tabular}

Table 3. Percentage of individuals with mild, moderate and severe hopelessness.

\begin{tabular}{cc}
\hline Hopelessness & Percentage \\
\hline Minimal & 23.80 \\
Mild & 19.04 \\
Moderate & 47.61 \\
Severe & 9.52 \\
\hline
\end{tabular}

Table 4. Correlation between depression and hopelessness.

\begin{tabular}{cccccc} 
& Mean & Standard Deviation & $\Gamma$ & $p$ \\
\hline Depression & 15.76 & 8.80 & & \\
Hopelessness & 8.85 & 5.35 & & \\
\hline${ }^{\mathrm{a} p}<0.05$. & & & & \\
\end{tabular}

The results reveal that $38 \%$ participants are mildly depressed and $47 \%$ are moderately hopeless residing in the old age homes. Additionally, a positive strong correlation between the variables (depression and hopelessness) has been observed $(\Gamma=0.83, p<0.05)$.

\section{Discussion}

The present study aimed to assess the presence and severity of depression and hopelessness in institutionalized elderly using Beck’s Depressive Inventory (BDI II) and Beck’s Hopelessness Scale (BHS). Results of the study indicate presence of mild depression and moderate hopelessness in the current sample population. Further, a positive correlation between depression and hopelessness amongst the institutionalized participants was also found in the study.

Depression is a pathological process at any age. Depression in old age is an emerging public health problem leading to morbidity and disability that needs immediate attention (Rajkumar, Thangadurai, Senthilkumar, Gayathri, Prince, \& Jacob, 2009). It presents in many ways in elderly people, reflecting the increasing diversity found with ageing (Evans \& Mottram, 2000).

A contributing factor to the growing rate of depression in India involving the change in life style pattern, surroundings and environment is a source of stress. The rapid transformation in social structure and in traditional value system has had a tremendous impact on the wellbeing of the elderly (Bothrea \& Dasgupta, 2011); therefore the changing forms of socialization, need of belongingness and care are vital contributing factors (Singh \& Misra, 2009). For instance, a change in the joint family structure to a nuclear family (Reddy \& Chandrashekar, 1998) involves limited time spent with limited family members.

A similar scenario is observed at the old age homes as they (elderly) are faced with a completely different setting, daily routine and variety of new people. The elderly modify behavior and actions according to the amended 
social group. This further affects their thought process and possibly increases the need of establishing a sense of belongingness in the changed setting. They are less satisfied with the manner in which they handle their problems and social life (WHO, 2012; Satcher, 2000).

According to the results of this study, it was found that there was a $38.09 \%$ of Mild Depression among the participants which may be attributed to the change in lifestyle that they have experienced from moving from the family to an institution setup and the lack of familial support.

Researchers have found that about $25.94 \%$ of physically ill elderly residents of nursing home have substantially higher levels of depression than among older adults living at home (Sood, Singh, \& Gargi, 2006). Further, it has been established that the type of relationship shared or established also impacts the individuals at the old age homes. Persons with a positive relationship tend to be less affected by everyday problems and have a greater sense of control. Those without relationships often become isolated, ignored, and depressed. Those caught in poor relationships tend to develop and maintain negative perceptions of self, are less satisfied and often lack the motivation to change (Hanson \& Carpenter, 1994). Wallace and O'Harra (1992) conducted a longitudinal study which indicates that increasing illness and reduced social support are indicative of the onset of depression. Lack of meaningful relationships, loss of loved ones, and physiological distress are likely to exacerbate depressive symptoms. In addition, a strong positive correlation between Hopelessness and Depression in the participants of the present study was found. Researchers have concluded that people who are depressed struggling with feelings of hopelessness and helplessness more so than people who are not depressed (Sacco \& Beck, 1995). A sense of hopelessness reflects a negative view of the future which reinforces the depressive thoughts. A study conducted by NIMHANS found that one in every 15 adult Indians, suffer from depressive illness and as much as $40 \%$ of the population is likely to cross the line of clinical depression. WHO (2002) states that depression threatens to be the world's most common illness by the end of the century.

Besides socialization, the other aspect contributing to the depressive and hopelessness feelings of the participants include the environmental conditions of the old age homes and care institutions. Previous research has found that the nursing home environment appears to reinforce passive, apathetic, and dependent behavior, which can lead to motivational and affective problems (Kahana, Kahana, \& Riley, 1989). Furthermore, learned helplessness stemming from a sense of lack of control or inadequate reinforcement for independent behavior can add to severity of depression.

However, it is found that the therapeutic and nontherapeutic interventions used in elderly homes can affect the wellbeing and negative effects of illness (Joshi, Kumar, \& Avasthi, 2003). Research studies have suggested that Yoga intervention appears to improve the quality of life and sleep quality of elderly living in old age homes (Hariprasad et al., 2013). Thus, focused interventions by trained personnel at care institutions can be beneficial and improve the mental health conditions of the participants. They could serve and compensate for the availability of immediate family support and care.

Overall, the findings of the study have implications for socio/psychological well-being of elderly population. Severity of stressful events is an indicator of how likely a person develops a disorder. Stressful events such a grief, loss of activity, lack of familial support and financial support are contributing factors which play a significant role in depression. However, these can be restrained if identified earlier and through immediate support. The environment of old age homes and institutions is apathetic in our country, which adds to the negative expectancy and thought process that already exists in elderly. Improving the infrastructure, training the care takers and availability of necessary intervention will further reduce the impact of precipitating factors of any mental disorder in the adult population.

The study, despite being comprehensive, has certain limitations, which may be addressed in follow-up researches. First, the old age homes were not selected on a constant criterion thus, effecting the conditions and services provided to the participants as well as the demographic characteristics for financial support. Second, the results cannot be generalized as the study lacks a homogeneous sample that is, limited sample size; varied chronic illnesses and stay period of participants. Also, this is an exploratory study for which no power calculations were made for the small sample size.

Despite these limitations, the study sheds light on the relationship between depression and hopelessness of institutionalized elderly in India as a societal concern. With the growing life expectancy rate, the elderly population are vulnerable and at high risk for the development of mental disorder and must be addressed.

In order to improve the health status of the elderly population it is important to carry out more studies in different areas and larger samples to identify various factors that are related to psychological distress and disability, 
which should lead to efforts to develop effective programmes in disease.

\section{References}

Andrade, L., \& Caraveo, A. (2003). Epidemiology of Major Depressive Episodes: Results from the International Consortium of Psychiatric Epidemiology (ICPE) Surveys. International Journal of Methods in Psychiatric Research, 12, 3-21. http://dx.doi.org/10.1002/mpr.138

APA (American Psychological Association) (2010). Understanding Depression and Effective Treatment. http://www.apa.org/helpcenter/understanding-depression.aspx

Bagge, C. L., Lamis, D. A., Nadorff, M., \& Osman, A. (2014). Relations between Hopelessness, Depressive Symptoms and Suicidality: Mediation by Reasons for Living. Journal of Clinical Psychology, 70, 18-31. http://dx.doi.org/10.1002/jclp.22005

Barua, A., \& Kar, N. (2010). Screening for Depression in Elderly Indian Population. Indian Journal of Psychiatry, 52, 150153. http://dx.doi.org/10.4103/0019-5545.64595

Beck, A. T., Steer, R. A., \& Brown, G. K. (1996). Manual for the Beck Depression Inventory-II. San Antonio, TX: Psychological Corporation.

Beck, A. T., Weissman, A., Lester, D., \& Trexler, L. (1974). The Measurement of Pessimism: The Hopelessness Scale. Journal of Consulting and Clinical Psychology, 42, 861-865.

Blazer, D. G. (2003). Depression in Late Life: Review and Commentary. Journal of Gerontology: Medical Science, 58, 245269. http://dx.doi.org/10.1093/gerona/58.3.m249

Bothrea, M., \& Dasgupta, M. (2011). A Comparative Psychosocial Study of Selected Elderly Groups in the Canvas of Successful Ageing. Ageing and Society Journal, 21, 1-24.

Carson, R. C., Butcher, V. J., Mineka, S., \& Hooley, M. I. (2007). Abnormal Psychology. New Delhi: Pearson.

Djernes, J. K. (2006). Prevalence and Predictors of Depression in Populations of Elderly: A Review. Acta Psychiatica Scandinavica, 113, 372-387. http://dx.doi.org/10.1111/j.1600-0447.2006.00770.x

Dunn, S. L. (2005). Hopelessness as a Response to Physical Illness. Journal of Nursing Scholarship, 37, 148-154. http://dx.doi.org/10.1111/j.1547-5069.2005.00027.x

Duran, V. M., \& Barlow, D. H. (2000). Abnormal Psychology: An Introduction. Belmont: Wadsworth.

Evans, M., \& Mottram, P. (2000). Diagnosis of Depression in Elderly Patients. Advances in Psychiatric Treatment, 6, 49-56. http://dx.doi.org/10.1192/apt.6.1.49

Hansson R. O., \& Carpenter B. N. (1994). Relationships in Old Age: Coping with the Challenge of Transition. New York: Guilford Press.

Hariprasad, V. H., Varambally, S., Shivakumar, V., Kalmady, S. V., Venkatasubramanian, G., \& Gangadhar, B. N. (2013). Effects of Yoga Intervention on Sleep and Quality of Life in Elderly: A Randomized Controlled Trial. Indian Journal of Psychiatry, 55, 394-396.

Joshi, K., Kumar, R., \& Avasthi, A. (2003). Morbidity Profile and Its Relationship with Disability and Psychological Distress among Elderly People in Northern India. International Journal Epidemiology, 32, 978-987. http://dx.doi.org/10.1093/ije/dyg204

Kahana, E., Kahana, B., \& Riley, K. (1989). Person-Environment Transactions Relevant to Control and Helplessness in Institutional Settings. Psychological Perspectives of Helplessness and Control in the Elderly, 57, 121-153. http://dx.doi.org/10.1016/S0166-4115(08)60979-6

Math, S. B., \& Srinivasaraju, R. (2010). Indian Psychiatric Epidemiological Studies: Learning from the Past. Indian Journal of Psychiatry, 52, 95-103. http://dx.doi.org/10.4103/0019-5545.69220

McMillan, D., Gilbody, S., Beresford, E., \& Neilly, L. (2007). Can We Predict Suicide and Non-Fatal-Self Harm with the Beck Hopelessness Scale? A Meta-Analysis. Psychological Medicine, 37, 769-778. http://dx.doi.org/10.1017/S0033291706009664

Nandi, P. S., Banerjee, G., Mukherjee, S., Nandi, S., \& Nandi, D. (1997). A Study of Psychiatric Morbidity in an Elderly Population in a Rural Community in West Bengal. Indian Journal of Psychiatry, 39, 122-129.

Pilania, M., Bairwa, M., Kumar, N., Khanna, P., \& Khurana, H. (2013). Elderly Depression in India: An Emerging Public Health Challenge. The Academy of Management Journal, 6, 107-111. http://dx.doi.org/10.4066/amj.2013.1583

Puwac, H. (1995). Slow Irreversibility. Bucharest: Publishing Expert.

Rajkumar, A. P., Thangadurai, P., Senthilkumar, P., Gayathri, K., Prince, M., \& Jacob, K. S. (2009). Nature, Prevalence and Factors Associated with Depression among the Elderly in a Rural South Indian Community. International Psychogeriatric, 21, 372-378. http://dx.doi.org/10.1017/S1041610209008527 
Reddy, V. M., \& Chandrashekar, C. R. (1998). Prevalence of Mental and Behavioural Disorders in India: A Meta-Analysis. Indian Journal of Psychiatry, 40, 149-157.

Runcan, P. L. (2012). Elderly Institutionalization and Depression. Procedia-Social and Behavioral Sciences, 33, $109-113$. http://dx.doi.org/10.1016/j.sbspro.2012.01.093

Sacco, W. P., \& Beck, A. T. (1995). Cognitive Theory and Therapy. In E. Edward Beckham, \& W. R. Leber (Eds.), Handbook of Depression: Treatment, Assessment and Research (2nd ed., 628 p.). New York: Guilford Press.

Satcher, D. (2000). Mental Health: A Report of the Surgeon General-Executive Summary. Journal of the American Medical Association, 31, 15-23. http://dx.doi.org/10.1037/0735-7028.31.1.5

Singh, A., \& Misra, N. (2009). Loneliness, Depression, and Sociability in Old Age. Industrial Psychiatry Journal, 18, 51-55. http://dx.doi.org/10.4103/0972-6748.57861

Smarr, K. L., \& Keefer, A. L. (2011). Measures of Depression and Depressive Symptoms. Arthritis Care and Research, 63, 454-466. http://dx.doi.org/10.1002/acr.20556

Sood, A., Singh, P., \& Gargi, P. D. (2006). Psychiatric Morbidity in Non-Psychiatric Geriatric Inpatients. Indian Journal of Psychiatry, 48, 56-61.

Stotland, E. (1969). The Psychology of Hope. San Francisco: Jossey-Bass.

Vink, D., Aartsen, M. J., \& Schoevers, R. A. (2008). Risk Factors for Anxiety and Depression in the Elderly: A Review. Journal of Affective Disorder, 106, 29-44. http://dx.doi.org/10.1016/j.jad.2007.06.005

Wallace, J., \& O’Hara, M. W. (1992). Increases in Depressive Symptom-Atology in the Rural Elderly: Results from a CrossSectional and Longitudinal Study. Journal of Abnormal Psychology, 101, 398-404. http://dx.doi.org/10.1037/0021-843X.101.3.398

Whipple, M. O., Lewis, T. T., Sutton-Tyrrell, K., Matthews, K. A., Barinas-Mitchell, E., Powell, L. H. et al. (2009). Hopelessness, Depressive Symptoms and Carotid Atherosclerosis in Women: The Study of Women's Health across the Nation (SWAN) Heart Study. Stroke: A Journal of Cerebral Circulation, 40, 3166-3172 http://dx.doi.org/10.1161/STROKEAHA.109.554519

WHO (World Health Organization) (2002). Conquering Depression: You Can Get Out of the Blues. New Delhi: WHO Regional Office for South-East Asia.

WHO (World Health Organization) (2012) Depression: A Global Crisis (p. 7). Occoquan: World Federation for Mental Health. http://hesp-news.org/2012/10/12/depression-a-global-crisis/

\section{Submit or recommend next manuscript to SCIRP and we will provide best service for you:}

Accepting pre-submission inquiries through Email, Facebook, LinkedIn, Twitter, etc.

A wide selection of journals (inclusive of 9 subjects, more than 200 journals)

Providing 24-hour high-quality service

User-friendly online submission system

Fair and swift peer-review system

Efficient typesetting and proofreading procedure

Display of the result of downloads and visits, as well as the number of cited articles

Maximum dissemination of your research work

Submit your manuscript at: http://papersubmission.scirp.org/ 